\title{
Obituário do Professor Sebastião de Almeida Prado Sampaio Obituary of Professor Sebastião de Almeida Prado Sampaio"
}

\author{
Evandro A. Rivitti ${ }^{1}$
}

Em 18 de outubro, faleceu o prof. Sebastião Sampaio, abrindo irreparável lacuna na Dermatologia Brasileira e Internacional. Seu desaparecimento físico, no entanto, não impedirá sua sobrevivência espiritual junto aos colegas dermatologistas, para os quais representou liderança marcante por suas características pessoais. O prof. Sampaio aliava à sua formação técnica primorosa, inteligência brilhante, tirocínio clínico especial e inigualável capacidade de trabalho. Esse conjunto de qualidades tornava-o médico ímpar.

O prof. Sampaio nasceu em Casa Branca, interior de São Paulo, em 1919, graduando-se em medicina pela Faculdade de Medicina da Universidade de São Paulo, em 1943, ano em que, a convite do prof. Aguiar Pupo, começou a trabalhar como assistente voluntário na Clínica Dermatológica, efetivando-se como assistente em 1946. Em 1950, foi aprovado em concurso de livre-docência, elaborando tese sobre lúpus eritematoso, doença mal conhecida até então, e da qual estudou dezesseis casos, casuística praticamente inédita na época.

Em 1951, o prof. Sampaio completou sua formação no exterior, trabalhando com o prof. Paul O'Leary na Mayo Foundation for Medical Education and Research, um dos maiores centros médicos dos Estados Unidos. Em 1960, assumiu a cátedra de dermatologia da FMUSP e foi o responsável pela introdução da moderna dermatologia nessa escola médica.

Com sua sensibilidade e experiência que inclui prática no exterior, o prof. Sampaio realizou a transição da dermatologia morfológica, tradicional, para a dermatologia moderna, que aplica as ciências básicas no entendimento da fisiopatologia, na diagnose e terapêutica das doenças da pele. Exímio histopatologista, o prof. Sampaio incutiu e difundiu entre seus discípulos a importância dessa subespecialidade da dermatologia. Introduziu a discussão diária de casos com grande proveito para professores e alunos. Dinamizou a Clínica Dermatológica, fazendo-a funcio-

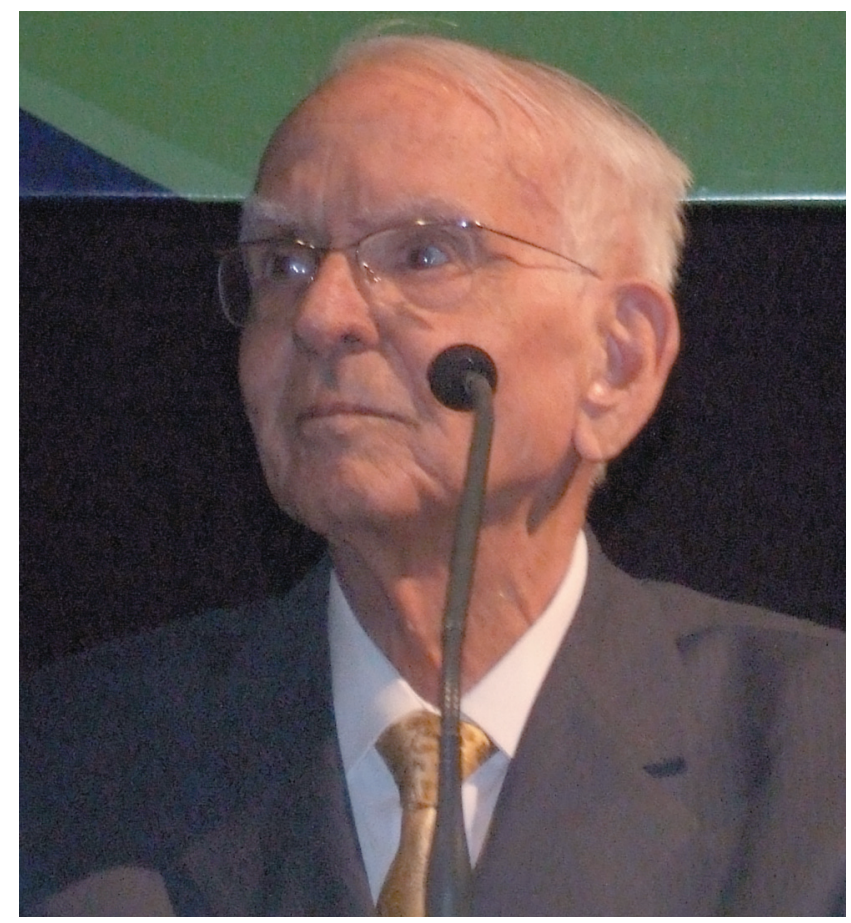

nar não só no período da manhã, mas também à tarde, e, através do estímulo constante aos discípulos para freqüentar congressos e reuniões científicas no país e no exterior, projetou a dermatologia brasileira nos grandes foros da especialidade.

Como professor, Sampaio contribuiu para a formação de mais de 300 médicos do país e do exterior na especialidade, e, desses, mais de duas dezenas galgaram importantes postos acadêmicos em escolas médicas brasileiras e de outros países. Educador rigoroso, era extremamente exigente com seus discípulos, observando a apresentação do médico, a pontualidade e a postura ética frente ao doente.

São Paulo, Novembro de 2008.

Professor Titular da Universidade de São Paulo (USP) - São Paulo (SP), Brasil. 
A produção científica do prof. Sampaio está expressa em mais de 120 publicações nacionais e estrangeiras, destacando-se algumas notáveis contribuições científicas, como a introdução e a padronização do tratamento da paracoccidioidomicose com anfotericina B. Experimentando inicialmente a droga com o prof. Carlos da Silva Lacaz, em sua tese de professorado, o prof. Sampaio não apenas demonstrou cabalmente a importância dessa medicação, particularmente nos casos graves da paracoccidioidomicose, como também desenvolveu a metodologia de sua aplicação, de forma a minimizar seus efeitos colaterais através da administração simultânea de hidrocortisona e, se necessário, dipirona - procedimento ainda hoje utilizado. De grande importância é seu trabalho em parceria com o prof. Raymundo Martins Castro, demonstrando a grande eficácia da anfotericina B no tratamento das formas mucosas de leishmaniose tegumentar americana, geralmente resistentes aos antimoniais e de alta morbidade.

O prof. Sampaio também participou, com o prof. Luiz Carlos Cucé, dos primeiros trabalhos estudando a utilização dos novos antifúngicos imidazólicos no tratamento de micoses superficiais e profundas. E foi responsável pela padronização do tratamento da pitiríase versicolor com imidazólicos, determinando ser de 10 dias o tempo de tratamento suficiente para a erradicação do fungo com essas drogas.

No campo da clínica, o prof. Sampaio descreveu, na pseudopelada de Brocq, sinal que, entre nós, leva seu nome - "sinal de Sampaio" - e se traduz pela presença de massa gelatinosa no nível da porção bulbar de cabelos arrancados da área lesada. Quando presente, esse sinal indica atividade da doença.

Além das importantes contribuições científicas, o prof. Sampaio, sempre em contato com os grandes centros dermatológicos mundiais, introduziu, pionei- ramente no país, inovações técnicas importantes, como o laboratório de imunodermatologia, a criocirurgia com nitrogênio líquido e a cirurgia micrográfica de Mohs, moderna técnica, indispensável ao tratamento adequado de cânceres cutâneos, particularmente algumas formas de carcinoma basocelular recidivados, tumores de anexos, tumor de Merckel e dermatofibrossarcoma, entre outros.

O prof. Sampaio teve sempre intensa atividade societária junto à Sociedade Brasileira de Dermatologia e sociedades internacionais, tendo sido membro, por muitos anos, do Comitê Internacional de Dermatologia, órgão máximo da dermatologia mundial. Fundou a seção de São Paulo da Sociedade Brasileira de Dermatologia, a Sociedade Brasileira de Cirurgia Dermatológica e a Sociedade Brasileira de Dermopatologia.

Foi um dos fundadores da Radla (Reunião Anual dos Dermatologistas Latino-Americanos). Foi, também, presidente do Cilad (Colégio Ibero-LatinoAmericano de Dermatologia).

Ainda no âmbito científico, o prof. Sampaio fundou, junto com o prof. Luís Díaz, dos Estados Unidos, o Grupo Cooperativo para Estudo do Fogo Selvagem, que, há mais de 15 anos, vem produzindo importantes trabalhos voltados para a busca da etiologia dessa enfermidade.

Mesmo gravemente doente, o prof. Sampaio participava ativamente das atividades dermatológicas e emocionou todos ao comparecer, em setembro último, ao Congresso Brasileiro de Dermatologia, em que ministrou conferência sobre sua extraordinária experiência em acne e seu tratamento.

Sua última lição não foi de dermatologia, mas de vida, mostrando incomum coragem ao enfrentar a doença, a proximidade da morte e a própria morte, enriquecendo ainda mais seu legado aos pósteros. 